Journal of Humanities and Social Sciences Studies (JHSSS)

ISSN: 2663-7197

DOI: $10.32996 /$ jhsss

Journal homepage: https://al-kindipublisher.com/index.php/jhsss

\title{
Air Quality Trends amid Covid-19 Lockdown in Metro Manila, Philippines: A Preliminary Case Review \\ Jasmen S. Pasia ${ }^{1}$, EnP Moises C. Torrentira, Jr. PhD' ${ }^{2}$, Hazel C. Navarra ${ }^{3}$, and Michael Makilan ${ }^{4}$ \\ ${ }^{1}$ Faculty, San Pedro College, Davao City, Philippines \\ ${ }^{2}$ Professor, University of Southeastern Philippines-Mintal Campus, Davao City, Philippines \\ ${ }^{3}$ Faculty, Brokenshire College of Davao, Davao City, Philippines \\ ${ }^{4}$ Emergeny MEAL Officer, Oxfam Philippines \\ Corresponding Author: EnP. Moises C. Torrentira Jr. E-mail: moises.torrentira@usep.edu.ph
}

\section{ARTICLE INFORMATION}

Received: October 05, 2020

Accepted: November 25, 2020

Volume: 2

Issue: 6

DOI: $10.32996 /$ jhsss.2020.2.6.16

\section{KEYWORDS}

Air quality trends, COVID-19

pandemic, lockdown, Metro

Manila, Philippines

\section{ABSTRACT}

CoVID-19 pandemic forced a countrywide lockdown in the Philippines from March 16, 2020 to May 15, 2020 and extended to May 31, 2020 in Metro Manila and some parts of Central Luzon. Because of these forced restrictions, the air pollution level in Metro Manila drastically slowed down just a few weeks upon the implementation of the lockdown. Therefore, this study aimed to establish a preliminary case review on the implications of the lockdown to the air quality in the country's capital with the aid of data from the Centre for Research on Energy and Clean Air (CREA) and Airtoday.ph station. The empirical analysis revealed that when Metro Manila was under Enhanced Community Quarantine (ECQ), tropospheric nitrogen oxide (NO2) dropped by approximately $52 \%$ compared to the 2019 levels in the same period. The city also registered the lowest PM 2.5 air pollution levels during the first 30 days of the lockdown with an average of 11.59 $\mathrm{ug} / \mathrm{m} 3$. Moreover, the satellite image from the Institute of Environmental Science and Meteorology (IESM), UP Diliman showed a lower Atmospheric Optical Depth (AOD) of 0.01 , which means that the air is clean during the lockdown period when compared with the AOD value during the same period in 2018 and 2019. At the Lung Center of the Philippines, a comparison of pre-ECQ and ECQ air quality levels showed that PM2.5 is reduced from $80 \%$ to $180 \%$, particularly during evenings and early mornings. A similar trend along EDSA Munoz, where $70-90 \%$ reduction of PM 2.5 was observed since the ECQ. Overall, the study revealed that lockdown measures, fortunately, have brought the opportunity to rationalize human impact on the environment. Although we could say those travel restrictions or lockdown is an unconventional measure to air pollution prevention and control, it is possible to improve air quality by reducing nonessential individual movements by highlighting the importance of fuel-free activities or implementing short-term lockdowns (3-5 days).

\section{Introduction}

China reported another mysterious respiratory disease to World Health Organization (WHO) during the last few weeks of the year 2019, which was later identified as COVID-19 caused by coronavirus SARS-CoV 2 (Bao \& Zhang, 2020). The world's ground zero, Wuhan in Hubei province in central China, was heavily ravaged, forcing authorities to impose a lockdown in late January to contain the virus. However, efforts may be safely described as futile as the virus found its way to hosts outside China and on January 30, 2020, the WHO declared the outbreak a Public Health Emergency of International Concern (PHEIC) and on March 11, 2020, a "global pandemic" calling for an aggressive global response. As of this writing, the cumulative

\footnotetext{
K C AL-KINDI CENTER R D DERELOPMENT AN
} Your gatewoy to world-class research
Published by Al-Kindi Center for Research and Development. Copyright (c) the author(s). This is an open access article under CC BY license (https://creativecommons.org/licenses/by/4.0/) 
number of confirmed cases of COVID-19 has exceeded 8 million, and $>200$ countries and regions have been affected by the disease (WHO, 2020).

In the Philippines, the Department of Health (DoH) has registered the first SARS-CoV 2 infection on January 30, 2020, from a 38-year-old female Chinese National, and on March 7, 2020, the first local transmission of COVID-19 was confirmed.

Mobility restrictions, which include travel, were implemented to prevent the disease's spread from its source. The Philippines is among the first countries to implement this policy, which has been one of the effective response measures in health emergencies such as the N1H1 epidemic in 1999 (Paolo et al., 2011; Qi et al., 2016). The Philippine government imposed a lockdown, the longest so far in the country, that resulted in travel bans and limits of nonessential movements in and out of cities, suspension of all transports, and closure of some establishments such as malls, schools, and factories. Travel restrictions have since been reported to substantially mitigate the spread of COVID-2019 (Chinazzi et al., 2020; Kraemer et al., 2020; Tian et al., 2020).

During the pandemic, social distancing and quarantine protocols were strictly implemented by local governments around the globe (Torrentira, 2019). The unprecedented lockdown significantly decreased human mobility, economic production, and consumption activities (Bao \& Zhang, 2020; Kerimray et al., 2020), and consequently, many countries experienced a dramatic reduction in air pollution. In the Metropolitan City of Milan, the partial and total lockdown led to the significant reduction of pollutants concentration of SO2 and NO2 (Collivignarelli et al., 2020), while in megacity Delhi, India, air quality has significantly improved during the lockdown compared to the pre-lockdown with PM10 and PM2.5 recorded a maximum reduction of greater than 50\% (Mahato, Pal, \& Ghosh, 2020). In China, travel restrictions and factory closures produced a 25\% drop in CO2, as reported by Finland's Centre for Research on Energy and Clean Air (Carbon Brief 2020). Also, the European Space Agency (ESA) satellite imagery showed a significant decline in NO2 emissions coinciding with the lockdowns between January 1 to March 11, 2020, in northern Italy (Bao \& Zhang, 2020). There is empirical evidence that suspension of transportation, closure of industries, schools, and other economic activities decrease anthropogenic emissions, such as PM2.5 concentrations (Wang et al., 2020).

Relevant literature search revealed that pollution is relative to economic growth; that is, an increase or decrease in economic activity will increase or decrease pollution, respectively (Raupach et al., 2007; Wang and Su, 2020; Wang et al., 2019).

In particular, air pollution is caused by human-related activities, such as traffic and transportation (Chen et al., 2017, Fu \& Gu, 2017; Lin Lawell et al., 2011) and industrial production (Cole et al., 2005). Extreme measures such as the lockdown will slow down if not cease human production and consumption activities, positively impacting air quality.

Will the economic slide during the lockdown improve air quality? This is the question the group attempted to address; hence, this paper described the air quality index amid the COVID-19 lockdown and hopefully provide a baseline theoretical reference that would lead to impact studies and in-depth discussions on the changes of significant air pollutant emissions as a result of the decrease in human-related activities.

\section{Methodology}

Despite the diligent efforts of the group to retrieve the air quality index during the period of the lockdown through the Environmental Monitoring Board (EMB) website, only real-time data is provided every visit to the website; hence, secondary data were retrieved online from the Centre for Research on Energy and Clean Air (CREA) and Airtoday.ph station. However, only data from Metro Manila is available. According to Torrentira (2020), with the need to continue the conduct of research even amid the COVID-19 threat, the data collection methodologies and processes need to be innovated. Hence, in this study, any available data online that could aid in answering the objective were utilized

\section{Results and Discussion}

\subsection{Air Quality Trends in Metro Manila}

Figure 1a shows that from 15 March to 15 May 2020, when Metro Manila, Philippines, was under Enhanced Community Quarantine (ECQ), levels of tropospheric nitrogen oxide (NO2) dropped by approximately 52\% in comparison with the 2019 levels on the same period. Moreover, Metro Manila registered the lowest PM2.5 air pollution levels during the first 30 days of the lockdown with an average of $11.59 \mathrm{ug} / \mathrm{m3}$, as shown in Figure 1b. The drastic reduction of NO2 and PM2.5 is mainly caused by a significant drop in transportation as social and economic activities were restricted to essential services in Metro Manila and between surrounding provinces. 


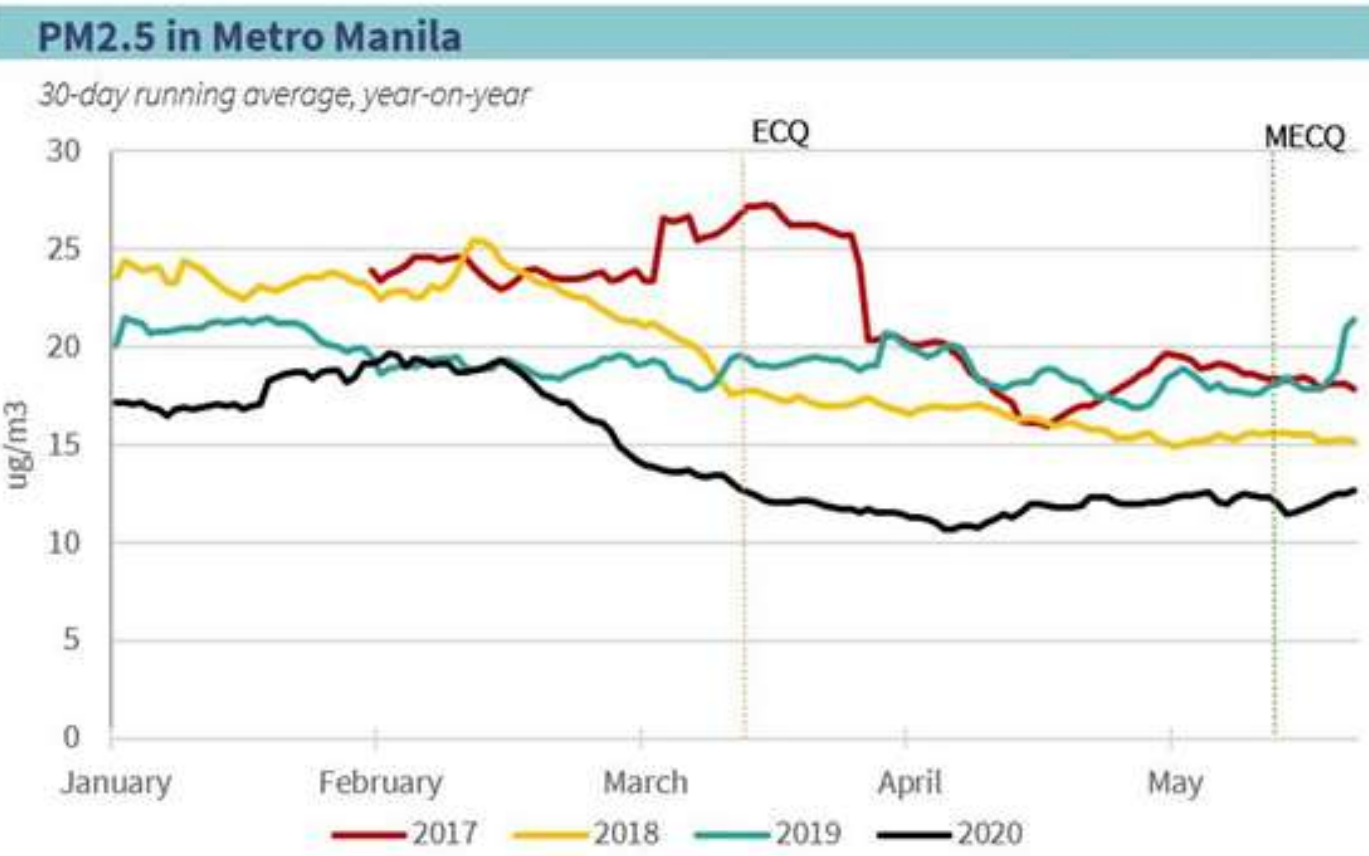

Figure 1a. Monthly average PM2.5 in Metro Manila from 2017-2020

\section{Change in Average PM2.5 in Metro Manila}

30-day running average, compared with 2019

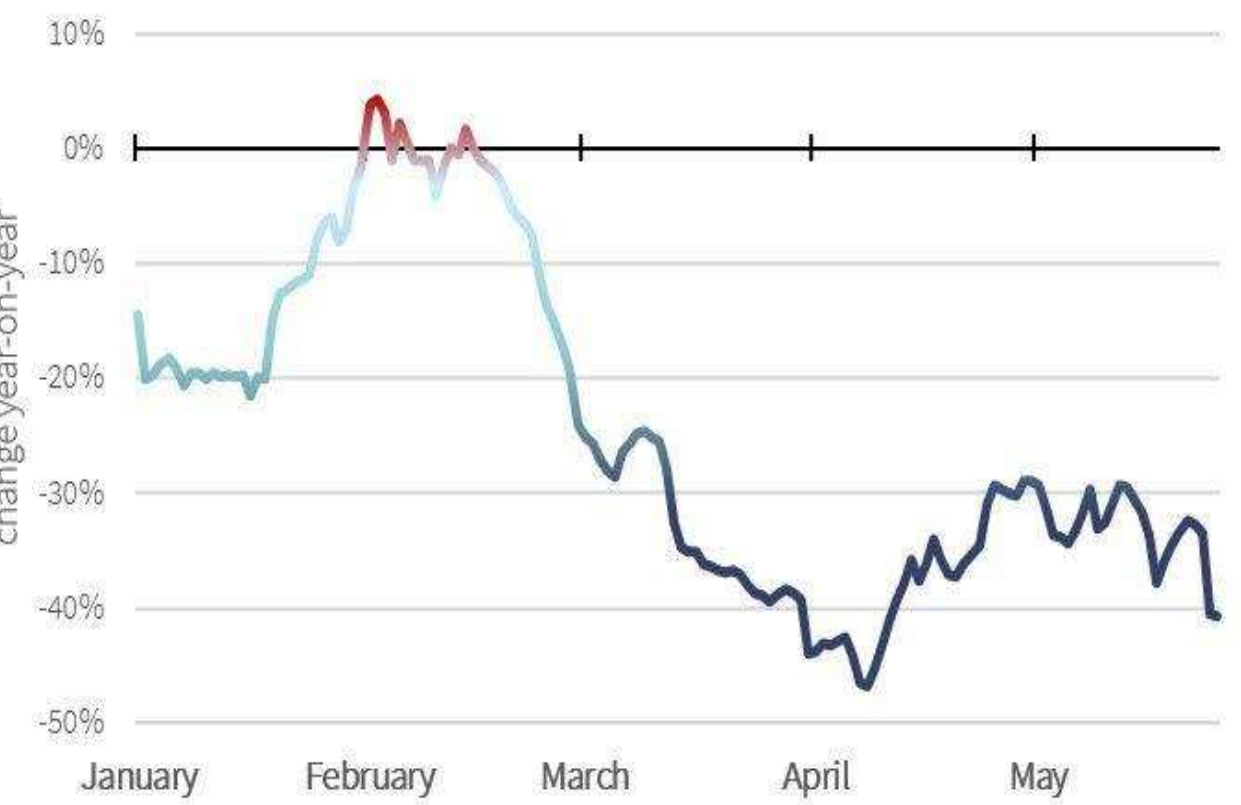

Figure 1b. Change in average PM2.5 in Metro Manila in a 30-day running average compared with 2019 data 
Figure $2 \mathrm{a}$ is an Airtoday.ph station report at the Lung Center of the Philippines where a comparison of pre-ECQ and ECQ air quality levels show the best improvement during evenings and early mornings, PM2.5 is reduced from $80 \%$ to $180 \%$. Meanwhile, Figure $2 b$ depicts a similar trend in another Airtoday.ph station along EDSA Munoz, where $70-90 \%$ reduction of PM 2.5 was observed since the ECQ.

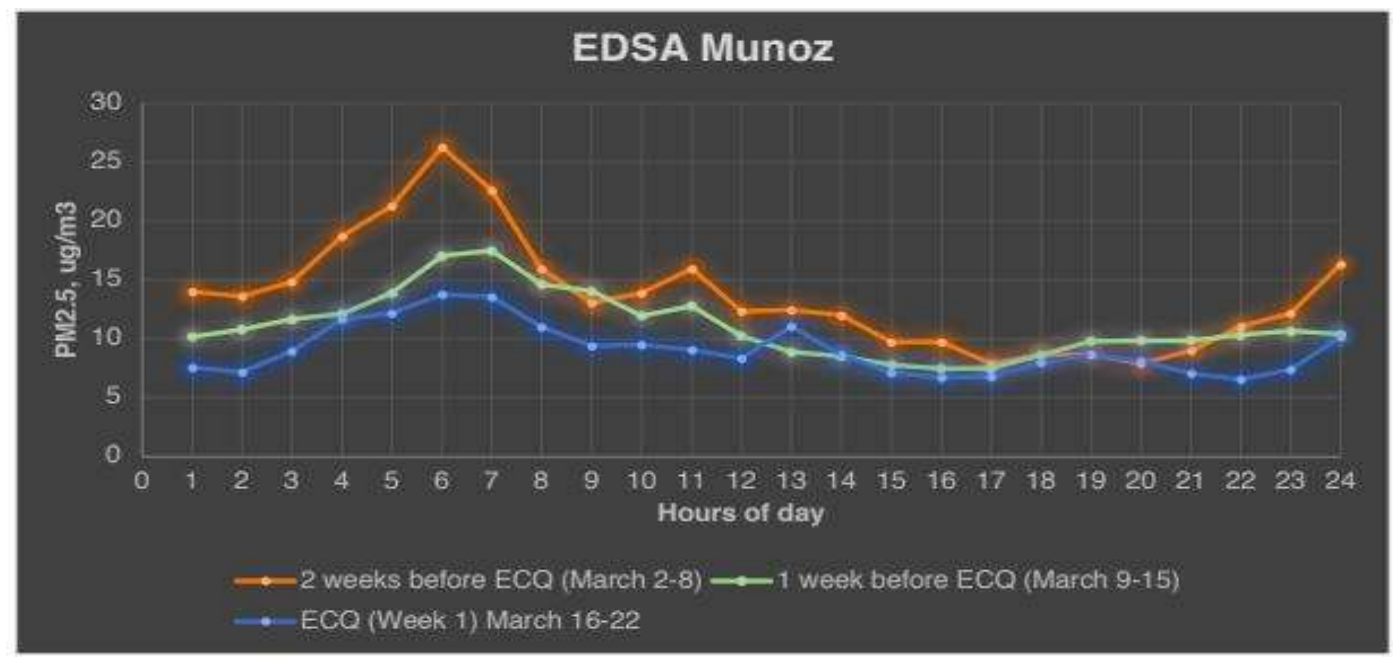

Figure 2b. Comparison of Pre- ECQ and ECQ levels of particulate matter (Source: Environmental Pollution Studies

\subsection{Laboratory of IESM-CS-UP Diliman}

Particulate matter or air pollutants contain a mixture of solid particles or liquid droplets in the atmosphere, such as water, dust, and salt particles. In high concentration, this would make the skies look hazy. This finding explains higher visibility and clearer skies in Metro Manila during the lockdown period.

\subsection{Satellite Images}

The satellite image from the Institute of Environmental Science and Meteorology (IESM), UP Diliman using Himawari satellite used by PAGASA for weather monitoring showed a lower Atmospheric Optical Depth (AOD) of 0.01, which means that the air is clean during the lockdown period (Figure 3b) compared with the AOD value during the same period in 2018 and 2019 (Figure 3a). AOD measures how sunlight is reflected from the Earth as it is blocked or scattered by particulate matter or air pollutants; thus, a value greater than 0.5 means hazy conditions. Therefore, during the lockdown, Metro Manila's air quality is better, and there is less air pollution.

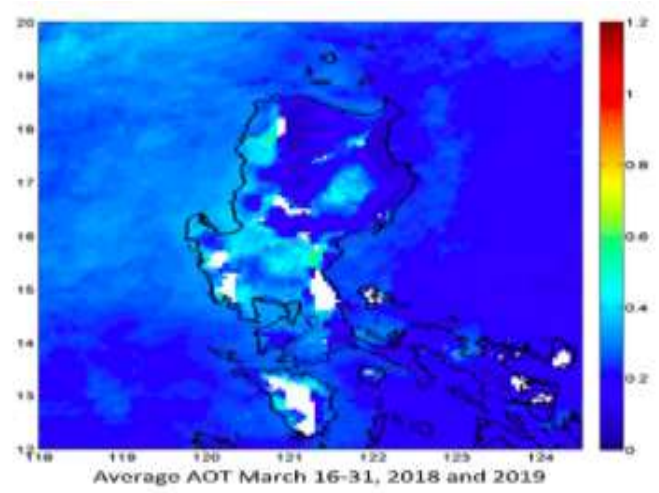

Figure 3a. Satellite image of AOD in Motro Manila Maroh $16-312018=2019$

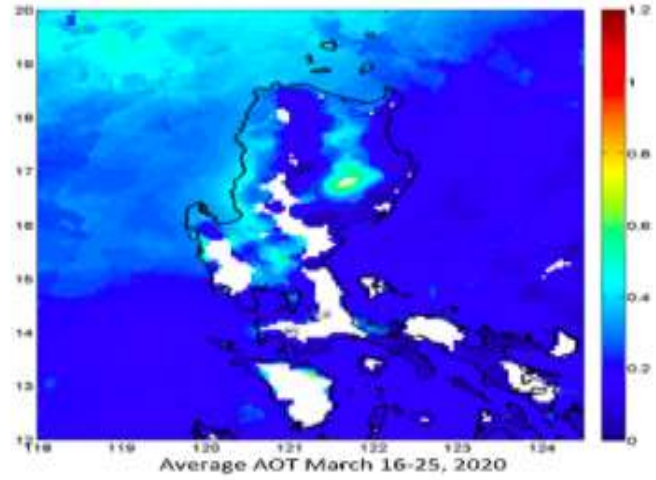

Figure 3b. Satellite image of AOD in Metro Manila Maroh 16 25,2020 


\section{Conclusion}

SARS-COV 2 caught the world unprepared in almost all human survival dimensions, but its presence may be a blessing-indisguise for our environment. Fortunately, the lockdown measures in different parts of the world have brought opportunities to rationalize the environment's human impact. Therefore, this preliminary review results may help us rethink how far we are responsible for the catastrophes we experienced nowadays. According to a Greenpeace study, air pollution has been a perennial problem in the country, affecting $98 \%$ of the population and responsible for more than 27,000 deaths in 2018 alone. Before the lockdown, the Philippines ranked 57th out of 98 countries in IQAir's "World most polluted countries," as PM2.5 was recorded at an average of 17.6 micrograms per cubic meter $(\mu \mathrm{g} / \mathrm{m3})$ in 2019, an increase from $14.6 \mu \mathrm{g} / \mathrm{m} 3 \mathrm{in} 2018$ (Mongabay News, 23 April 2020).

In general, this preliminary case review showed that lockdown and restriction measures of human activities significantly reduced air pollution emissions. The empirical analysis revealed that from 15 March to 15 May 2020, when Metro Manila, Philippines was under Enhanced Community Quarantine (ECQ), levels of tropospheric nitrogen oxide (NO2) dropped by approximately $52 \%$ in comparison with the 2019 levels on the same period registering the lowest PM2.5 air pollution levels during the first 30 days of the lockdown with an average of $11.59 \mathrm{ug} / \mathrm{m} 3$. Clear skies, breathtaking sunsets, and the Sierra Madre as a backdrop to the sprawling city went viral just a week after the government suspended public transportation and nonessential businesses to contain the virus.

These findings corroborate with the study done in Delhi, India, where air quality data of seven pollutant parameters: PM10, $\mathrm{PM} 2.5, \mathrm{SO} 2, \mathrm{NO} 2, \mathrm{CO}, \mathrm{O} 3$, and $\mathrm{NH} 3$ showed significant reduction among 34 monitoring stations during the lockdown period (Mahato et al., 2020). Similar results were also reported in China; about 30\% NO2 and 25\% carbon emission have reduced in the lockdown state (He et al., 2020; Liu et al., 2020). A study also identified diminishing air pollutants over the world's major cities where the outbreak of COVID 19 is very high (Cadotte, 2020). The survey by Ogen (2020) showed a strong linkage between the concentration of NO2 and the fatal outcome caused by COVID-19.

While there are several limitations of this case review, such as complete AQI monitoring data for statistical analysis to have a better projection and inference on the impact of the lockdown amid COVID-19, our findings imply that human-related activities influence air quality. Although we could say that travel restrictions or lockdown is an unconventional measure to air pollution prevention and control, it is possible to improve air quality by reducing nonessential individual movements by highlighting the importance of fuel-free activities such as green commuting. This case review can serve as a useful supplement to the regulatory agencies such as the Department of Environment and Natural Resources (DENR) through the EMB to rethink of the existing regulatory plans and perhaps will give a baseline data towards considering the implementation of strict alternative measures like short-term lockdown (3-5 days) to control air quality. However, this alternative should be studied rigorously vis-à-vis its effect on the economy as cost-effectiveness will be one of the critical issues for policymakers when deciding alternative control measures. The case review only presented data in Metro Manila, AQI during the lockdown across the country's major cities such as Cebu and Davao would have shed a better picture of the impact of the lockdown on air quality.

Funding: This research received no external funding and is part of the academic requirement for Environment and Natural Resource Policies of the PhD Program of UseP-CDM SY 2019-2020.

Conflicts of Interest: The authors declare no conflict of interest.

\section{References}

Bao, R., \& Zhang, A. (2020). Does lockdown reduce air pollution? Evidence from 44 cities in northern China. Science of the Total Environment, 139052.

[1] Berger, B. (2020). Can working remotely lead us to a cleaner world? Retrieved from https://www.triplepundit.com/story/2020/canworking-remotely-lead-us-cleaner-world/120326

[2] Cadotte, M. (2020). Early evidence that COVID-19 government policies reduce urban air pollution.

[3] Chen, D., Liu, X., Lang, J., Zhou, Y., Wei, L., Wang, X., Guo, X. (2017). Estimating the contribu- tion of regional transport to PM_(2.5) air pollution in a rural area on the North China Plain. Sci. Total Environ. 583, 280-291. https://doi.org/10.1016/j.scitotenv.2017.01.066.

[4] Collivignarelli, M. C., Abbà, A., Bertanza, G., Pedrazzani, R., Ricciardi, P., \& Miino, M. C. (2020). Lockdown for CoViD-2019 in Milan: What are the effects on air quality?. Science of The Total Environment, 732, 139280.

[5] Fu, S., Gu, Y. (2017). Highway toll and air pollution: evidence from Chinese cities. Journal of Environmental Economics \& Management https://doi.org/10.1016/j. jeem.2016.11.007.

[6] He, G., Pan, Y., Tanaka, T. (2020). COVID-19, city lockdowns, and air pollution: evidence from China. medRxiv https://doi.org/10.1101/2020.03.29.20046649 20046649. 
[7] Kerimray, A., Baimatova, N., Ibragimova, O. P., Bukenov, B., Kenessov, B., Plotitsyn, P., \& Karaca, F. (2020). Assessing air quality changes in large cities during COVID-19 lockdowns: The impacts of traffic-free urban conditions in Almaty, Kazakhstan. Science of the Total Environment, 139179.

[8] Lin Lawell, C.Y.C., Zhang, W., Umanskaya, V., 2011. The Effects of Driving Restrictions on Air Quality: São Paulo, Bogotá, Beijing, and Tianjin.

[9] Liu, F., Page, A., Strode, S.A., Yoshida, Y., Choi, S., Zheng, B., Lamsal, L.N., Li, C., Krotkov, N.A., Eskes, H., van der, A.R., 2020. Abrupt declines in tropospheric nitrogen dioxide over China after the outbreak of COVID-19. arXiv preprint arXiv:2004.06542.

[10] Mahato, S., Pal, S., \& Ghosh, K. G. (2020). Effect of lockdown amid COVID-19 pandemic on air quality of the megacity Delhi, India. Science of the Total Environment, 139086.

[11] Ogen, Y., 2020. Assessing nitrogen dioxide (NO2) levels as a contributing factor to the co- ronavirus (COVID-19) fatality rate. Sci. Total Environ. 138605

[12] Paolo, B., Chiara, P., Ramasco, J.J., Michele, T., Vittoria, C., Alessandro, V., Matjaz, P., (2011). Human mobility networks, travel restrictions, and the global spread of 2009 H1N1 pandemic. PLoS One 6, e16591. https://doi.org/10.1371/journal. pone.0016591.

[13] Qi, W., E., T.J., Adriana, B.L., (2016). Patterns and limitations of urban human mobility resil- ience under the influence of multiple types of natural disaster. PLoS One 11, e147299. https://doi.org/10.1371/journal.pone.0147299.

[14] Raupach, M.R., Marland, G., Ciais, P., Le Quéré, C., Canadell, J.G., Klepper, G., et al., 2007. Global and regional drivers of accelerating CObsubN2b/subN emissions. Proc. Natl. Acad. Sci. 104, 10288-10293.

[15] Sabillo, K. (2020). Beyond lockdown: Can the Philippines sustain low air? Retrieved from https://earthjournalism.net/stories/beyondlockdown-can-the-philippines-sustain-low-air-pollution-levels

[16] Torrentira, M. (2020). Online data collection as adaptation in conducting quantitative and qualitative research during the COVID-19 pandemic. European Journal of Education Studies. V. 7, Issue 11, pp 78-86.

[17] Wang, Q., Su, M., 2020. Drivers of decoupling economic growth from carbon emission - an empirical analysis of 192 countries using decoupling model and decomposition method. Environ. Impact Assess. Rev. 81, 106356.

[18] Wang, D., Hu, B., Hu, C., Zhu, F., Liu, X., Zhang, J., et al., (2020). Clinical characteristics of 138 hospitalized patients with 2019 novel coronavirus-infected pneumonia in Wuhan, China. JAMA 323, 1061-1069.

[19] Wang, P., Chen, K., Zhu, S., Wang, P., Zhang, H. (2020). Severe air pollution events not avoided by reduced anthropogenic activities during COVID-19 outbreak. Resour. Conserv. Recycl. 158, 104814. https://doi.org/10.1016/j.resconrec.2020.104814.

[20] WHO (2020). Timeline: Covid-19 in the Philippines. Retrieved from https://ph.news.yahoo.com/timeline-covid-19-philippines040500881.html

[21] Woodyat, A. (2020). India's carbon emissions drop for the first time in four decade. Retrieved from https://www.cnn.com/2020/05/12/india/india-carbon-emissions-fall-intl-scli/index.html

[22] World Health Organization. (2020). Coronavirus Disease (COVID-2019) Situation Reports Situation Report. https://www.who.int/docs/dfault-source/coronaviruse/situation-reports/20200618-covid-19-sitrep-150.pdf?sfvrsn=aa9fe9cf_2

[23] Sabillo, K. (2020). Beyond lockdown: Can the Philippines sustain low air? Retrieved from https://earthjournalism.net/stories/beyondlockdown-can-the-philippines-sustain-low-air-pollution-levels 